\title{
Dysplastic nevus associated with seborrheic keratosis*
}

\author{
Luciane Francisca Fernandes Botelho ${ }^{1}$ \\ Milvia Maria Simões e Silva Enokihara ${ }^{3}$
}

\author{
Nilceo Schwery Michalany ${ }^{2}$ \\ Sergio Henrique Hirata ${ }^{4}$
}

DOI: http://dx.doi.org/10.1590/abd1806-4841.20142222

\begin{abstract}
Seborrheic keratosis is a common skin lesion which may coincidentally be associated melanocytic nevi. The authors describe a case of dysplastic nevus associated with seborrheic keratosis and discuss the clinical, dermoscopic, and histological findings of this association. They also discuss the association between seborrheic keratosis and other benign and malignant tumours.

Keywords: Dermoscopy; Keratosis, seborrheic; Melanoma; Nevi and melanomas; Nevus
\end{abstract}

\section{INTRODUCTION}

Seborrheic keratoses are benign cutaneous non melanocytic tumours with specific clinical characteristics, which when present allow their diagnosis in the majority of cases. Many dermatologists therefore treat them without histological confirmation. However, some reviews have shown that errors can occur in clinical diagnosis or other associated lesions may be present. ${ }^{1}$

Atypical nevus is a risk marker for melanoma development; however, there is controversy about atypical nevus having a high transformation rate to melanoma. $^{2}$

Seborrheic keratosis is a common skin lesion; therefore some authors believe that melanocytic lesions could possibly be associated with this lesion. ${ }^{3}$

\section{CASE REPORT}

A 38-year-old woman presented a dark coloured papule at physical examination measuring $9 \mathrm{~mm}$ on the upper right back (Figure 1). Dermoscopy revealed asymmetrical shape, comedo-like openings, milia-like cysts, bluish veil, and granulation (Figure 2). Date of lesion appearance was not known. The following hypotheses were formulated: Seborrheic keratosis, lichen planus-like keratosis, melanoma, and atypical nevus. Exeresis with a $2 \mathrm{~mm}$ margin was indicated and histological study revealed hyperkeratosis, horny

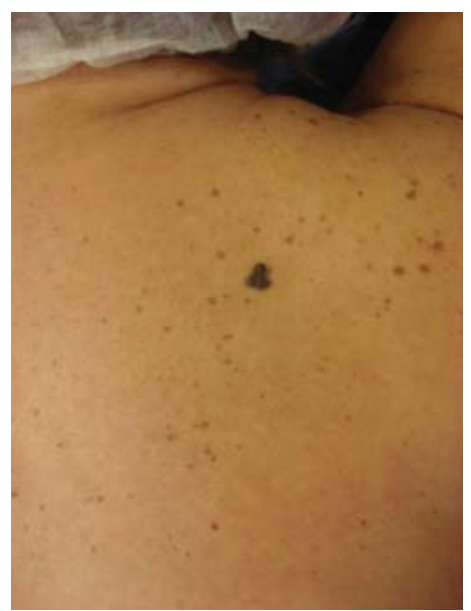

FIGURE 1: Dark coloured papule measuring $9 \mathrm{~mm}$ on upper right back

Approved by the Advisory Board and accepted for publication on 28.12.2012.

* Work performed at the Federal University of Sao Paulo (UNIFESP) - Sao Paulo (SP), Brazil.

Conflict of interest: None

Financial funding: None

Masters student, Department of Dermatology, Federal University of Sao Paulo (UNIFESP) - Sao Paulo (SP), Brazil.

Masters in General Anatomical Pathology - Associate Professor, Department of Pathology, Federal University of Sao Paulo (UNIFESP) - Sao Paulo (SP), Brazil. $\mathrm{PhD}$ in Pathology from Federal University of Sao Paulo (UNIFESP) - Dermatopathologist from Departments of Dermatology and Pathology, Federal University of Sao Paulo (UNIFESP) - Sao Paulo (SP), Brazil.

4 PhD in Dermatology from Federal University of Sao Paulo (UNIFESP) - Adjunct Professor, Department of Dermatology, Federal University of Sao Paulo (UNIFESP) - Sao Paulo (SP), Brazil. 


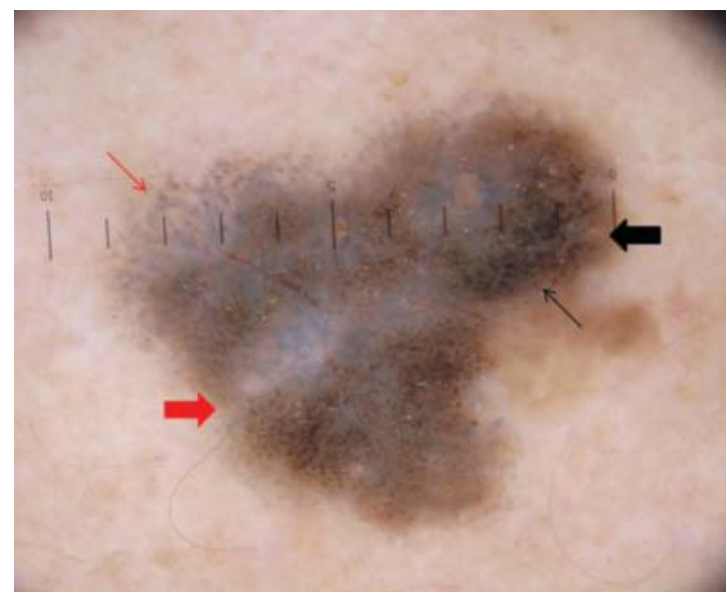

Figure 2: (Delta 20 dermatoscope): Asymmetric shape, many colours, comedo-like opening (fine black arrow), milia-like cyst (thick black arrow), bluish veil (thick red arrow), and granulation (thin red arrow)

pseudocysts, basaloid cells, presence of fusion of nests along the sides of rete ridges, concentric fibroplasia, atypical melanocytes, melanophages and discrete perivascular lymphocytic infiltrate. From this description the conclusion was seborrheic keratosis associated with dysplastic nevus (Figures 3 e 4).

\section{DISCUSSION}

The lesion in the above case presents comedolike opening and milia-like cysts. These structures are respectively described in $71 \%$ and $66 \%$ of seborrheic keratosis, and are rarely seen in lesions where melanoma is suspected. ${ }^{4}$ Although the lesion did not present criteria determining it as melanocytic, the remaining lesion characteristics, such as bluish veil and granulation justified excisional biopsy. In the histological study, comedo-like opening corresponded to invagination of the epidermis filled by keratin and milia-like cysts to small intra-epidermal cyst filled with keratin. ${ }^{4}$ The nests of nevus cells did not present correlation with the dermoscopy image, granulation in the lesion corresponded to melanophages in the dermis, and bluish veil corresponded to melanophages in the dermis associated to the area of hyperkeratosis.

An association between seborrheic keratosis and atypical nevus was found in two cases in a survey of 85 seborrheic keratosis lesions associated to premalignant and malignant lesions. Basal cell carcinoma was associated to $31.8 \%$ of cases, followed by squamous cell carcinoma $(8.2 \%)$ and melanoma $(8.2 \%){ }^{5}$ Cascajo et al. found 54 seborrheic keratoses associated

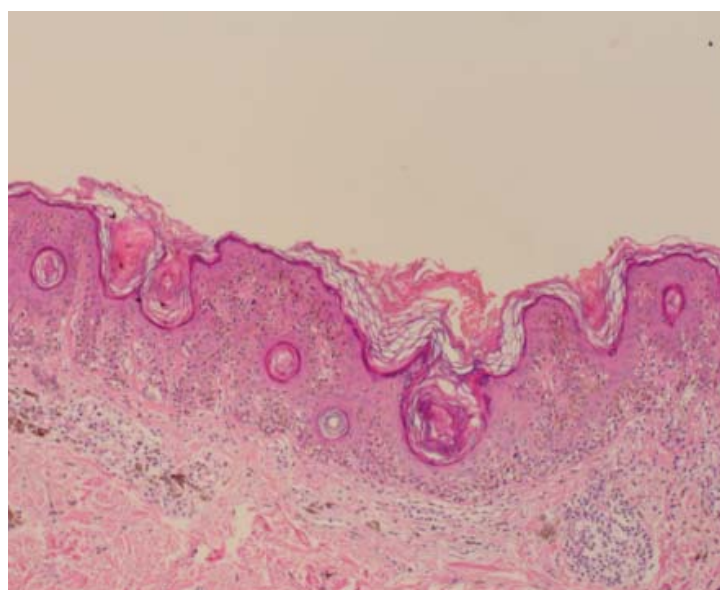

FIGURE 3: Presence of hyperkeratosis, horny pseudocysts and melanophages in the dermis, and discrete perivascular lymphocytic infiltrate (HE 100X)

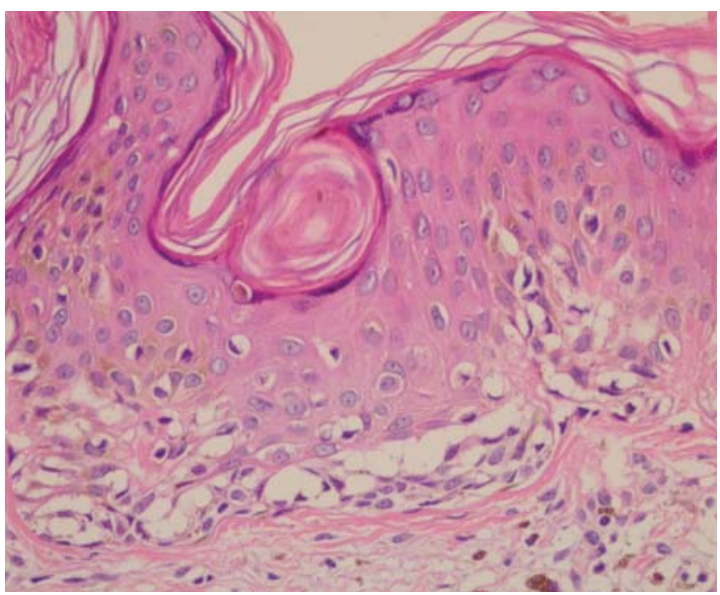

FIGURE 4: Presence of fusion of nests along the sides of rete ridges, concentric fibroplasia, atypical melanocytes, melanophages in the dermis, and proliferated basaloid cells (HE 400X)

to malignant lesions, of these 43 were basal cell carcinoma, six Bowen's disease, three keratoacanthomas, and two melanomas. ${ }^{6}$ Y Vun et al. analysed 823 seborrheic keratosis cases and found an association to malignancy in 43 lesions, however most cases were associated with in situ squamous cell carcinoma, and there were no seborrheic keratosis cases associated to melanoma or dysplastic nevus. ${ }^{7}$ With regard to the dermoscopic description of seborrheic keratosis associated to dysplastic nevus or melanoma, we found no 
articles in the English language describing this association. However, melanoma mimicking seborrheic keratosis at dermoscopic examination has been described. ${ }^{8}$

Lesions diagnosed as seborrheic keratosis should be sent for histological study. A study of 9204 lesions with clinical diagnosis of seborrheic keratosis, among the differentials diagnosis informed by the doctor, showed that 61 cases $(0.66 \%)$ were melanomas mimicking seborrheic keratosis. ${ }^{9}$

The approach for lesions exhibiting milia-like cysts and comedo-like openings must be cautious if dermoscopy also reveals suspicious structures. The dermoscope is an important instrument in managing pigmented lesions, but all the structures in a lesion should be analysed together to avoid mistakes in diagnosis. ${ }^{10}$

\section{REFERENCES}

1. Thomas I, Kihiczak NI, Rothenberg J, Ahmed S, Schwartz RA. Melanoma within the seborrheic keratosis. Dermatol Surg. 2004;30:559-61.

2. Rezze GG, Leon A, Duprat J. Dysplastic nevus (atypical nevus). An Bras Dermatol 2010;85:863-71.

3. Zabel RJ, Vinson RP, McCollough ML. Malignant melanoma arising in a seborrheic keratosis. J Am Acad Dermatol. 2000;42:831-3.

4. Braun RP, Rabinovitz HS, Krischer J, Kreusch J, Oliviero M, Naldi L, et al. Dermoscopy of pigmented seborrheic keratosis: a morphological study. Arch Dermatol. 2002;138:1556-60.

5. Lim C. Seborrhoeic keratoses with associated lesions: a retrospective analysis of 85 lesions. Australas J Dermatol. 2006:47:109-13.

6. Cascajo CD, Reichel M, Sánchez JL. Malignant neoplasms associated with seborrheic keratoses. An analysis of 54 cases. Am J Dermatopathol. 1996;18:278-82.

7. Vun Y, De'Ambrosis B, Spelman L, Muir JB, Yong-Gee S, Wagner G, et al. Seborrhoeic keratosis and malignancy: collision tumour or malignant transformation? Australas $\mathrm{J}$ Dermatol. 2006;47:106-8.

8. Argenziano G, Rossiello L, Scalvenzi M, Staibano S, Ruocco E, Cicale L, et al. Melanoma simulating seborrheic keratosis: a major dermoscopy pitfall. Arch Dermatol. 2003;139:389-91.

9. Izikson L, Sober AJ, Mihm MC Jr, Zembowicz A. Prevalence of melanoma clinically resembling seborrheic keratosis: analysis of 9204 cases. Arch Dermatol. 2002;138:1562-6.

10. Braga JC, Scope A, Klaz I, Mecca P, Spencer P, Marghoob AA. Melanoma mimicking seborrheic keratosis: an error of perception precluding correct dermoscopic diagnosis. J Am Acad Dermatol. 2008;58:875-80.

\author{
MAILING ADDRESS: \\ Luciane Francisca Fernandes Botelho \\ Rua Borges Lagoa, 508 \\ Vila Clementino \\ 04038-001. São Paulo, SP. \\ Email: lucianebotelho@hotmail.com
}

How to cite this article: Botelho LFF, Michalany NS, Enokihara MMSS, Hirata SH. Dysplastic nevus associated with seborrheic keratosis. An Bras Dermatol. 2014;89(1):160-2. 